\title{
Q-analysis in Materials Selection
}

\author{
Orchi Bhattacharyya and Shankar Chakraborty*
}

Department of Production Engineering, Jadavpur University, Kolkata - 700 032, West Bengal, India

\section{H R O N I C L E}

Article history:

Received March 14, 2014

Accepted September 2, 2014

Available online

September 52014

Keywords:

Material selection

Material properties

Multi-criteria decision-making

Q-analysis

\begin{abstract}
A B S T R A C T
The designers often face the problem of choosing the best fitted material for a specific application from a huge array of available alternatives while simultaneously fulfilling all the given design requirements. For dealing with the material selection problems, a systematic and efficient approach is thus necessary. Selection of an optimal material from among various alternatives based on different conflicting subjective as well as objective attributes can be defined as a typical multi-criteria decision-making (MCDM) problem. The material selection problems for diverse engineering applications have already been solved by the past researchers employing different MCDM approaches. In this paper, the feasibility of $Q$-analysis technique as an MCDM tool is explored for arriving at the most appropriate decision regarding materials selection. Its applicability is demonstrated with the help of four illustrative examples and its capability to provide almost accurate material selection decisions is also validated.
\end{abstract}

(C) 2015 Growing Science Ltd. All rights reserved.

\section{Introduction}

It is well established that materials play an important role in engineering design and subsequent manufacture of a component/product. Material selection is one of the most challenging issues in the design and development of products, and it is also critical for the success and competitiveness of the manufacturing organizations. An inappropriate selection of materials may result in damage or failure of a product and significantly decrease its performance. An ever-increasing availability of materials, with each having its own characteristics, applications, advantages and limitations, and having complex relationships with various selection parameters (criteria), has made the material selection process more challenging and complex than even before (Edwards, 2005). Selection of the most suitable material for a given application thus involves the study of a large number of factors, like mechanical, electrical and physical properties, and cost considerations of the materials. Material selection for engineering design needs a clear understanding of the functional requirements for each individual component/product and various important criteria need to be simultaneously considered. The core objective of a material selection procedure is to identify the material selection attributes; such as material cost, product shape, material impact on environment, performance characteristics,

* Corresponding author. Tel./Fax.: +91-33-2414-6153

E-mail address: s chakraborty00@yahoo.co.in (S. Chakraborty)

(C) 2015 Growing Science Ltd. All rights reserved. doi: $10.5267 /$ j.dsl.2014.9.001 
availability, fashion, market trends, cultural aspects, aesthetics, recycling and target group, and obtain the most appropriate combination of material selection attributes in conjunction with the feasible requirements. Thus, great efforts need to be extended to determine those conflicting attributes that influence material selection, eliminate the unsuitable materials and choose the proper material in order to strengthen the existing material selection procedure. Thus, the material selection process can be regarded as a multi-criteria decision-making (MCDM) problem. A systematic and efficient approach to material selection is necessary in order to select the best alternative for a given engineering application. MCDM methods are gaining importance as potential tools for analyzing and solving complex problems due to their inherent ability to judge different alternatives on various criteria for possible selection of the best option. MCDM analysis has some unique characteristics, like presence of multiple non-commensurable and conflicting criteria, different units of measurement among the criteria and presence of quite different alternatives. There are three main steps in any MCDM technique involving numerical analysis of alternatives, i.e. a) determining the relevant criteria and alternatives, b) attach numerical measures to the relative importance to criteria and impact of the alternatives on those criteria, and c) process the numerical values to determine a ranking of each alternative.

The earlier researchers have already applied several mathematical tools and techniques, specially MCDM methods, like graph theory and matrix approach (Rao, 2006), VIKOR (Vlse Kriterijumska Optimizacija Kompromisno Resenje) method and its different variants (Rao, 2008; Chatterjee et al., 2009; Jahan et al., 2011; Bahraminasab et al., 2011; Cavallini et al., 2013), technique for order performance by similarity to ideal solution (TOPSIS) (Shanian \& Savadogo, 2006; Thakker et al., 2008; Athanasopoulos et al., 2009; Chauhan \& Vaish, 2012; Jahan et al., 2012; Chauhan \& Vaish, 2013; Çalışkan et al., 2013; Çalışkan, 2013; Yousefpour \& Rahimi, 2014), ELECTRE (ELimination and Et Choice Translating REality) method (Chatterjee et al., 2009), preferential ranking methods (Chatterjee et al., 2011; Chatterjee \& Chakraborty, 2012; Maity et al., 2102; Çalışkan et al., 2013; Çalışkan, 2013), additive utility (UTA) method (Athawale et al., 2011), preference selection index method (Maniya \& Bhatt, 2010), multi-objective optimization on the basis of ratio analysis (MOORA) method (Karande \& Chakraborty, 2012), axiomatic design model (Cicek \& Celik, 2010), utility concept (Karande \& Chakraborty, 2013), desirability function approach (Karande \& Chakraborty, 2013), quality function deployment (QFD) technique (Cavallini et al., 2013; Prasad \& Chakraborty, 2013) and analytic network process (Milani et al., 2013) for materials selection. It is thus well established that MCDM methods are quite capable of solving different material selection problems accurately. However, a need is still felt to review those adopted MCDM methods, and implement further competent and advanced methods for empirical validation and testing of various available approaches. In this paper, the applicability and feasibility of an almost unexplored MCDM tool, i.e. $Q$-analysis is demonstrated with the help of four illustrative material selection examples.

\section{Q-analysis}

$Q$-analysis, developed by Atkin (Atkin, 1978), is basically an approach to study structural characteristics of social systems in which two sets of indicators, features or characteristics are related to each other. It involves relatively simple calculations, and once the approximate sets are defined along with their relationships, no further information about the system is required. It also provides an algebraic topological framework for data reduction to facilitate a macroscopic conceptualization of the systems. For this purpose, indices, like connectivity level, eccentricity and complexity are defined and interpreted. The application of $Q$-analysis starts with the following data matrix which may often be treated as a decision or evaluation matrix.

$A=\left[\begin{array}{cccc}a_{11} & a_{12} & \ldots & a_{1 n} \\ a_{21} & a_{22} & \ldots & a_{2 n} \\ \ldots & \ldots & \ldots & \ldots \\ a_{m 1} & a_{m 2} & \ldots & a_{m n}\end{array}\right]$ 
In case of a decision matrix, $m$ is the number of candidate alternatives, $n$ is the number of selection criteria and $a_{i j}$ is the performance of $i^{\text {th }}$ alternative with respect to $j^{\text {th }}$ criterion. The matrix, $A$ can be mapped into an incidence matrix, $B$ using a mapping function defined by a slicing or threshold parameter $\theta$ (Duckstein \& Nobe, 1997). This mapping is defined as follows:

$b_{i j}= \begin{cases}1 & \text { if } a_{i j} \geq 0 \\ 0 & \text { otherwise }\end{cases}$

where $b_{i j}$ is the element in $i^{\text {th }}$ row and $j^{\text {th }}$ column of the incidence matrix, $B$ and $a_{i j}$ is its counterpart in the data matrix. Subsequently, $Q$-analysis had been integrated with MCDM principles to develop a new technique as multi-criteria $Q$-analysis (MCQA) for choosing the most appropriate alternative for a given application (Hiessl et al., 1985; Duckstein et al., 1988). During the recent past, MCQA had been successfully applied to solve several decision-making problems, like performance evaluation of a distribution system (Duckstein, 1983), factory automation project selection (Chin et al., 1991), water resources management (Özelkan \& Duckstein, 1996; Pillai \& Srinivasa Raju, 1996; Eder et al., 1997; Srinivasa Raju \& Nagesh Kumar, 2001) and selection of a logistic-park location (Teng et al., 2007). In MCQA, apart from the initial decision matrix, a vector, $w$ is required to provide the relative importance or priorities of the considered criteria. As most of the MCDM problems have a weight on each criterion, those can be similar to MCQA method. Although MCQA can accept non-numerical scales for the criteria, but it is better computationally to quantify all the ratings/weights. Therefore, for MCQA, the decision matrix needs to be normalized employing the following two equations so that the most favorable value for each criterion being one and the least desirable being zero.

For beneficial criteria,

$r_{i j}=\frac{a_{i j}-\min \left(a_{i j}\right)}{\max \left(a_{i j}\right)-\min \left(a_{i j}\right)}$,

for non-beneficial criteria,

$r_{i j}=\frac{\max \left(a_{i j}\right)-a_{i j}}{\max \left(a_{i j}\right)-\min \left(a_{i j}\right)}$,

where $r_{i j}$ is the normalized value of $a_{i j}$. Now, $Q$-analysis is applied to the normalized decision matrix where the alternatives are the simplices and criteria are the vertices (Duckstein \& Nobe, 1997). Several slicing parameters $(\theta)$ can be used in $Q$-analysis, but in this paper, ten slicing parameters are adopted in equal intervals of one-tenth. The element of the incidence matrix, $B$ at slicing parameter value of $k$ which corresponds to slicing parameter $(1 / 10) k$ is formed as follows:

$b_{i j}^{k}= \begin{cases}1 & \text { if } a_{i j} \geq \theta^{k} \\ 0 & \text { otherwise }\end{cases}$

In MCQA, MCQA I adopts a project satisfaction index (PSI) and a project comparison index (PCI), while MCQA II uses a project discordance index (PDI). PSI is a utility-based index, whereas, PCI is an outranking-based index. The PSI value of an alternative is independent from the other alternatives, while the PCI value of an alternative is dependent on the criteria values for the other alternatives. The value of PSI for a particular alternative determines how well it satisfies the considered criteria and is expressed as below:

$\mathrm{PSI}_{i}=\sum_{j, k} \theta^{k} w_{j} b_{i j}$,

where $w_{j}$ is the weight or relative importance of $j^{\text {th }}$ criterion.

After computing the PSI values for all the alternatives, those values are normalized as follows: 
$\operatorname{PSIN}_{i}=\frac{\operatorname{PSI}_{i}}{\max \left(\mathrm{PSI}_{i}\right)}$.

On the other hand, the value of PCI basically ranks the alternatives by comparing the related $q$ connectivity. The shared face matrix $\left(S^{k}\right)$ is used here to find the number of common satisfied criteria between the alternatives, and the equivalence classes and $q$-connectivity are then easily found among the considered alternatives (Duckstein \& Nobe, 1997). The formulation of $S^{k}$ matrix is given as below:

$S^{k}=B^{k}\left(B^{k}\right)^{T}-e^{T} e$

where $\mathrm{e}=(1,1,1,1,1,1,1,1,1)$ (for nine alternatives).

Now, the PCI value for $i^{\text {th }}$ alternative is defined as follows:

$\mathrm{PCI}_{i}=\sum_{k} \theta^{k}\left[\hat{q}_{i k}-q_{i k}^{*}\right]$

where $\hat{q}_{i k}=s_{i i}^{k}$ and $q_{i k}^{*}=\max _{j \mid j \neq i} s_{i j}^{k}$. After computing the PCI values for all the alternatives, they are again normalized as below:

$\mathrm{PCIN}_{i}=\frac{\mathrm{PCI}_{i}}{\max \left(\mathrm{PCI}_{i}\right)}$

MCQA I determines the ranking of the alternatives using a rating index (RI) which can be given as follows:

$\mathrm{RI}_{i}=\left[\left(1-\mathrm{PSIN}_{i}\right)+\left(1-\mathrm{PCIN}_{i}\right)\right]$

When arranged in ascending order, a lower value of RI indicates a better alternative.

\section{Illustrative examples}

In order to justify the feasibility and solution accuracy of $Q$-analysis technique as an effective MCDM tool, the following four material selection problems are analyzed and subsequently solved.

\subsection{Example 1}

In the first example, a gear material selection problem as solved by Milani et al. (2005) is considered. For design and manufacture of gears, nine alternative gear materials were taken into account and their performances were evaluated based on five criteria, i.e. surface hardness ( $\mathrm{SH}$ ) (in Bhn), core hardness (CH) (in Bhn), surface fatigue limit (SFL) (in N/mm ${ }^{2}$ ), bending fatigue limit (BFL) (in $\mathrm{N} / \mathrm{mm}^{2}$ ) and ultimate tensile strength (UTS) (in N/mm ${ }^{2}$ ). Among those five criteria, core hardness is the only nonbeneficial attribute for which smaller values are recommended. The quantitative data for this gear material selection problem is provided in Table 1. Milani et al. (2005) applied entropy method to determine the criteria weights as $\mathrm{w}_{\mathrm{SH}}=0.172, \mathrm{w}_{\mathrm{CH}}=0.005, \mathrm{w}_{\mathrm{SFL}}=0.426, \mathrm{w}_{\mathrm{BFL}}=0.292$ and $\mathrm{w}_{\mathrm{UTS}}=$ 0.102 . These criteria weights are considered here for the subsequent MCQA-based analysis. Using Eqns. (3) and (4), the original decision matrix is first normalized, as given in Table 2, where all the normalized criteria values lie between 0 and 1 . Then employing ten slicing parameters in equal intervals of one-tenth and using Eqn. (5), ten incidence matrices are subsequently developed. One of those incidence matrices as developed for a slicing parameter value of 0.60 is exhibited in Table 3 . The relevant $S^{6}$ matrix at slicing parameter $\theta^{6}=0.60$ which is constructed by employing Eqn. (8), is given in Table 4. Now, for this gear material selection problem, the corresponding values of PSI, PSIN, PCI and PCIN are computed, as given in Table 5, which lead to the final calculation of 
material rating index (MRI) values for all the alternatives. When these indices are arranged in ascending order of their values, a material ranking list as 9-7-8-6-5-2-1-3-4 is derived which identifies carburised steel as the most appropriate material for gear manufacture, followed by surface hardened alloy steel. Cast iron is the worst choice of material for this application. Using TOPSIS method, Milani et al. (2005) obtained the ranking of the alternative materials as 9-8-6-5-4-2-1-3-7 which closely matches with the MCQA-based results, showing a high Spearman rank correlation coefficient of 0.8660 . Figure 1 graphically compares those two rank orderings.

Table 1

Decision matrix for gear material selection problem (Milani et al., 2005)

\begin{tabular}{|c|c|c|c|c|c|c|}
\hline Sl. No. & Material & $\mathrm{SH}$ & $\mathrm{CH}$ & SFL & BFL & UTS \\
\hline 1. & Cast iron & 200 & 200 & 330 & 100 & 380 \\
\hline 2. & Ductile iron & 220 & 220 & 460 & 360 & 880 \\
\hline 3. & S.G. iron & 240 & 240 & 550 & 340 & 845 \\
\hline 4. & Cast alloy steel & 270 & 270 & 630 & 435 & 590 \\
\hline 5. & Through hardened alloy steel & 270 & 270 & 670 & 540 & 1190 \\
\hline 6. & Surface hardened alloy steel & 585 & 240 & 1160 & 680 & 1580 \\
\hline 7. & Carburised steel & 700 & 315 & 1500 & 920 & 2300 \\
\hline 8. & Nitrided steel & 750 & 315 & 1250 & 760 & 1250 \\
\hline 9. & Through hardened carbon steel & 185 & 185 & 500 & 430 & 635 \\
\hline
\end{tabular}

Table 2

Normalized decision matrix for example 1

\begin{tabular}{cccccc}
\hline Sl. No. & SH & CH & SFL & BFL & UTS \\
\hline 1 & 0.0265 & 0.8846 & 0 & 0 & 0 \\
2 & 0.0619 & 0.7308 & 0.1111 & 0.3171 & 0.2604 \\
3 & 0.0973 & 0.5769 & 0.1880 & 0.2927 & 0.2422 \\
4 & 0.1504 & 0.3462 & 0.2564 & 0.4085 & 0.1094 \\
5 & 0.1504 & 0.3462 & 0.2906 & 0.5365 & 0.4219 \\
6 & 0.7080 & 0.5769 & 0.7094 & 0.7073 & 0.6265 \\
7 & 0.9115 & 0 & 0 & 1 & 1 \\
8 & 1 & 0 & 0.7863 & 0.8049 & 0.4531 \\
9 & 0 & 1 & 0.1453 & 0.4024 & 0.1328 \\
\hline
\end{tabular}

\section{Table 3}

Incidence matrix $\left(B^{6}\right)$ at slicing parameter $\theta^{6}=0.60$ for example 1

\begin{tabular}{cccccc}
\hline Sl. No. & SH & CH & SFL & BFL & UTS \\
\hline 1 & 0 & 1 & 0 & 0 & 0 \\
2 & 0 & 1 & 0 & 0 & 0 \\
3 & 0 & 0 & 0 & 0 & 0 \\
4 & 0 & 0 & 0 & 0 & 0 \\
5 & 0 & 0 & 1 & 1 & 0 \\
6 & 1 & 0 & 1 & 1 & 1 \\
7 & 1 & 0 & 0 & 1 & 0 \\
8 & 1 & 0 & 1 & 0 & 0 \\
\hline
\end{tabular}

\section{Table 4}

Matrix $\left(S^{6}\right)$ at slicing parameter $\theta^{6}=0.60$ for example 1

\begin{tabular}{ccccccccccc}
\hline Alternative & 1 & 2 & 3 & 4 & 5 & 6 & 7 & 8 & 9 \\
\hline 1 & 0 & 0 & -1 & -1 & -1 & -1 & -1 & -1 & 0 \\
2 & 0 & 0 & -1 & -1 & -1 & -1 & -1 & -1 & 0 \\
3 & -1 & -1 & -1 & -1 & -1 & -1 & -1 & -1 & -1 \\
4 & -1 & -1 & -1 & -1 & -1 & -1 & -1 & -1 & -1 \\
5 & -1 & -1 & -1 & -1 & -1 & -1 & -1 & -1 & -1 \\
6 & -1 & -1 & -1 & -1 & -1 & 3 & 3 & 2 & -1 \\
7 & -1 & -1 & -1 & -1 & -1 & 3 & 3 & 2 & -1 \\
8 & -1 & -1 & -1 & -1 & -1 & 2 & 2 & 2 & -1 \\
9 & 0 & 0 & -1 & -1 & -1 & -1 & -1 & -1 & 0 \\
\hline
\end{tabular}


Table 5

Material rating indices for example 1

\begin{tabular}{cccccc}
\hline Sl. No. & PSI & PSIN & PCI & PCIN & MRI \\
\hline 1 & 0.0180 & 0.0003 & 0 & 0 & 1.9997 \\
2 & 0.2624 & 0.0496 & 0 & 0 & 1.9504 \\
3 & 0.1683 & 0.0318 & 0 & 0 & 1.9682 \\
4 & 0.4502 & 0.0852 & 0 & 0 & 1.9148 \\
5 & 0.6880 & 0.1302 & 1.4 & 0 & 1.8968 \\
6 & 2.7137 & 0.5135 & 3.4 & 0.4120 & 1.0745 \\
7 & 5.2840 & 0.6209 & 0 & 0 & 0 \\
8 & 3.2810 & 0.0704 & 1 & 0.2940 & 1.3791 \\
9 & 0.3723 & & & & 1.6356 \\
\hline
\end{tabular}

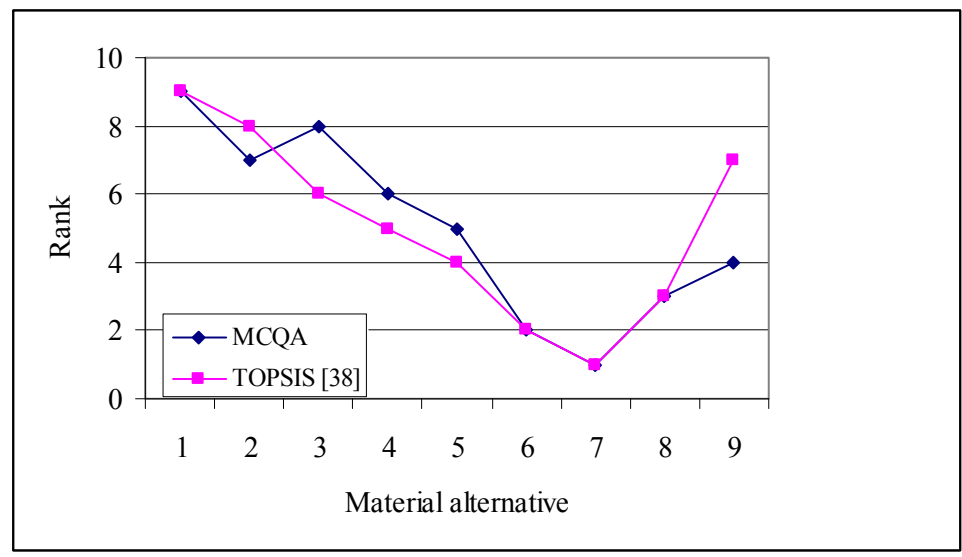

\subsection{Example 2}

Fig. 1. Comparison of material rankings for example 1

In this problem, the most suitable material for designing a cryogenic storage tank for transportation of liquid nitrogen is considered. For this purpose, the candidate material must have some desirable properties, like good weldability and processability, lower density and specific heat, smaller thermal expansion coefficient and thermal conductivity, adequate toughness at the operating temperature, and sufficient strength and stiffness. Table 6 provides the properties of the candidate materials for this problem, which has seven criteria and seven alternatives (Dehghan-Manshadi et al., 2007). Among these criteria, toughness index (TI), yield strength (YS) (in MPa) and Young's modulus (YM) (in $\mathrm{GPa}$ ) are the beneficial attributes, and density (D) $\left(\right.$ in $\left.\mathrm{g} / \mathrm{cm}^{3}\right)$, thermal expansion coefficient (TE) (in $10^{-6} /{ }^{\circ} \mathrm{C}$ ), thermal conductivity (TC) (in cal $/ \mathrm{cm}^{2} / \mathrm{cm} /{ }^{\circ} \mathrm{C} / \mathrm{s}$ ) and specific heat $(\mathrm{SH})\left(\mathrm{in} \mathrm{cal} / \mathrm{g} /{ }^{\circ} \mathrm{C}\right.$ ) are the non-beneficial attributes. Dehghan-Manshadi et al. (2007) determined the weights of those seven criteria as $\mathrm{w}_{\mathrm{TI}}=0.2140, \mathrm{w}_{\mathrm{YS}}=0.1550, \mathrm{w}_{\mathrm{YM}}=0.1190, \mathrm{w}_{\mathrm{D}}=0.1900, \mathrm{w}_{\mathrm{TE}}=0.1550, \mathrm{w}_{\mathrm{TC}}=0.0830$ and $\mathrm{w}_{\mathrm{SH}}=0.0830$, and observed the ranking of the alternative materials as 5-7-1-4-2-3-6 applying a modified digital logic technique. These sets of criteria weights are also used here for the subsequent analysis.

\section{Table 6}

Decision matrix for cryogenic storage tank material selection problem (Dehghan-Manshadi et al., 2007)

\begin{tabular}{|c|c|c|c|c|c|c|c|c|}
\hline Sl. No. & Material & TI & YS & YM & $\mathrm{D}$ & TE & $\mathrm{TC}$ & $\mathrm{SH}$ \\
\hline 1. & Al 2024-26 & 75.5 & 420 & 74.2 & 2.8 & 21.4 & 0.37 & 0.16 \\
\hline 2. & Al5052-0 & 95 & 91 & 70 & 2.68 & 22.1 & 0.33 & 0.16 \\
\hline 3. & SS 301-FH & 770 & 1365 & 189 & 7.9 & 16.9 & 0.04 & 0.08 \\
\hline 4. & SS 310-3AH & 187 & 1120 & 210 & 7.9 & 14.4 & 0.03 & 0.08 \\
\hline 5. & Ti-6Al-4V & 179 & 875 & 112 & 4.43 & 9.4 & 0.016 & 0.9 \\
\hline 6. & Inconel 718 & 239 & 1190 & 217 & 8.51 & 11.5 & 0.31 & 0.07 \\
\hline 7. & $70 \mathrm{Cu}-30 \mathrm{Zn}$ & 273 & 200 & 112 & 8.53 & 19.9 & 0.29 & 0.06 \\
\hline
\end{tabular}


The normalized decision matrix is developed in Table 7. Tables 8 and 9 respectively show the incidence matrix $\left(B^{8}\right)$ and the corresponding $S^{8}$ matrix at a slicing parameter value of 0.80 . The material rating indices are given in Table 10. When these values are sorted in ascending order, a ranking of materials as 5-7-1-3-2-4-6 is attained. SS 301-FH gains the top position in the list and A15052-0 is the worst material. When this rank ordering is compared with that obtained by DehghanManshadi et al. (2007), an excellent Spearman's rank correlation coefficient of 0.9600 is achieved.

Table 7

Normalized decision matrix for example 2

\begin{tabular}{ccccccccc}
\hline Sl. No. & TI & YS & YM & D & TE & TC & SH \\
\hline 1 & 0 & 0.2582 & 0.0286 & 0.9795 & 0.0552 & 0 & 0.8809 \\
2 & 0.0281 & 0 & 0 & 1 & 0 & 0.1130 & 0.8809 \\
3 & 1 & 1 & 0.8095 & 0.1077 & 0.4095 & 0.9322 & 0.9762 \\
4 & 0.1605 & 0.8077 & 0.9524 & 0.1077 & 0.6063 & 0.9604 & 0.9762 \\
5 & 0.1490 & 0.6154 & 0.2857 & 0.7009 & 1 & 1 & 0 \\
6 & 0.2354 & 0.8626 & 1 & 0.0035 & 0.8346 & 0.1695 & 0.9881 \\
7 & 0.2844 & 0.0855 & 0.2857 & 0 & 0.1732 & 0.2260 & 1 \\
\hline
\end{tabular}

Table 8

Incidence matrix $\left(B^{8}\right)$ at slicing parameter $\theta^{8}=0.80$ for example 2

\begin{tabular}{cccccccc}
\hline Sl. No. & TI & YS & YM & D & TE & TC & SH \\
\hline 1 & 0 & 0 & 0 & 1 & 0 & 0 & 0 \\
2 & 0 & 0 & 0 & 1 & 0 & 0 & 1 \\
3 & 1 & 1 & 1 & 0 & 0 & 1 & 1 \\
4 & 0 & 1 & 1 & 0 & 1 & 1 & 1 \\
5 & 0 & 0 & 0 & 0 & 1 & 0 & 1 \\
6 & 0 & 1 & 1 & 0 & 0 & 0 \\
7 & 0 & 0 & 0 & 0 & 0 & 1 \\
\hline
\end{tabular}

Table 9

Matrix $\left(S^{8}\right)$ at slicing parameter $\theta^{8}=0.80$ for example 2

\begin{tabular}{cccccccc}
\hline Sl. No. & TI & YS & YM & D & TE & TC & SH \\
\hline 1 & 1 & 1 & 0 & 0 & -1 & 0 & 0 \\
2 & 1 & 1 & 0 & 0 & -1 & 0 & 0 \\
3 & 0 & 0 & 4 & 3 & 0 & 2 & 0 \\
4 & 0 & 0 & 3 & 3 & 0 & 2 & 0 \\
5 & -1 & -1 & 0 & 0 & 1 & 0 & -1 \\
6 & 0 & 0 & 2 & 2 & 0 & 3 & 0 \\
7 & 0 & 0 & 0 & 0 & -1 & 0 & 0 \\
\hline
\end{tabular}

Table 10

Material rating indices for example 2

\begin{tabular}{|c|c|c|c|c|c|}
\hline Sl. No. & PSI & PSIN & PCI & PCIN & MRI \\
\hline 1 & 0.6750 & 0.1328 & 0.2 & 0.0345 & 1.8327 \\
\hline 2 & 0.6610 & 0.1300 & 0 & 0 & 1.8700 \\
\hline 3 & 5.0828 & 1 & 5.8 & 1 & 0 \\
\hline 4 & 2.5913 & 0.5098 & 2.5 & 0.4310 & 1.0592 \\
\hline 5 & 1.3394 & 0.2635 & 5.6 & 0.9655 & 0.7710 \\
\hline 6 & 2.9615 & 0.5826 & 1.5 & 0.2586 & 1.1588 \\
\hline 7 & 0.6860 & 0.1350 & 0 & 0 & 1.8650 \\
\hline
\end{tabular}

\subsection{Example 3}

In this example, an insulation material selection problem for computer cables is solved applying $Q$ analysis approach. Jahan et al. (2012) also solved that problem consisting of six materials and six criteria, as shown in Table 11, using a target-based normalization technique. These six criteria are dielectric strength (DS) $(\mathrm{V} / \mathrm{mm})$, volume resistance $(\mathrm{VR})(\mathrm{ohm} / \mathrm{cm})$, dissipation factor (DF) $(60 \mathrm{~Hz})$, 
dielectric constant (DC) $(60 \mathrm{~Hz})$, thermal expansion $(\mathrm{TE})\left(10^{-5} /{ }^{\circ} \mathrm{C}\right)$ and relative cost $(\mathrm{RC})$. Here, dielectric constant, relative cost and dissipation factor are non-beneficial attributes; dielectric strength and volume resistance are beneficial attributes, and a target value of $2.3 \times 10^{-5} /{ }^{\circ} \mathrm{C}$ is set for thermal expansion. Combining the subjective and objective weights, Jahan et al. (2012) determined the final criteria weights as $\mathrm{w}_{\mathrm{DS}}=0.1847, \mathrm{w}_{\mathrm{VR}}=0.2758, \mathrm{w}_{\mathrm{DF}}=0.1444, \mathrm{w}_{\mathrm{DC}}=0.1148, \mathrm{w}_{\mathrm{TE}}=0.0911$ and $\mathrm{w}_{\mathrm{RC}}$ $=0.1892$, which are also used here for the MCQA-based approach.

Table 12 provides the normalized decision matrix for this material selection problem for computer cables. The incidence matrix $\left(B^{2}\right)$ and the related $S^{2}$ matrix at a slicing parameter of 0.20 are respectively shown in Tables 13 and 14. Table 15 exhibits the computed values of material rating indices. After arranging these indices in ascending order, a ranking list as 1-3-2-5-6-4 is derived. PTFE is identified as the best material for computer cables, whereas, polysulfone is the worst choice. A Spearman's rank correlation coefficient of 0.8300 is achieved when this rank ordering is compared with that of Jahan et al. (2012).

\section{Table 11}

Decision matrix for insulation material for computer cables (Jahan et al., 2012)

\begin{tabular}{cccccccc}
\hline S1. No. & Material & DS & VR & DF & DC & TE & RC \\
\hline 1 & PTFE & 14820 & 10000 & 0.0002 & 2.1 & 9.5 & 4.5 \\
2 & CTFE & 21450 & 10000 & 0.0012 & 2.7 & 14.4 & 9 \\
3 & ETFE & 78000 & 100 & 0.0006 & 2.6 & 9 & 8.5 \\
4 & Polyphenylene oxide & 20475 & 1000 & 0.0006 & 2.6 & 6.5 & 2.6 \\
5 & Polysulfone & 16575 & 1 & 0.0010 & 3.1 & 5.6 & 3.5 \\
6 & Polypropylene & 21450 & 100 & 0.0005 & 2.2 & 8.6 & 1 \\
\hline
\end{tabular}

\section{Table 12}

Normalized decision matrix for example 3

\begin{tabular}{|c|c|c|c|c|c|c|}
\hline Sl. No. & DS & VR & DF & $\mathrm{DC}$ & TE & $\mathrm{RC}$ \\
\hline 1 & 0 & 1 & 1 & 1 & 0.4432 & 0.5625 \\
\hline 2 & 0.1049 & 1 & 0 & 0.4 & 1 & 0 \\
\hline 3 & 1 & 0.0099 & 0.6 & 0.5 & 0.3864 & 0.0625 \\
\hline 4 & 0.0895 & 0.0999 & 0.6 & 0.5 & 0.1023 & 0.8 \\
\hline 5 & 0.0278 & 0 & 0.2 & 0 & 0 & 0.6875 \\
\hline 6 & 0.1049 & 0.0099 & 0.7 & 0.9 & 0.3409 & 1 \\
\hline
\end{tabular}

\section{Table 13}

Incidence matrix $\left(B^{2}\right)$ at slicing parameter $\theta^{2}=0.20$ for example 3

\begin{tabular}{ccccccc}
\hline Sl. No. & DS & VR & DF & DC & TE & RC \\
\hline 1 & 0 & 1 & 1 & 1 & 1 & 1 \\
2 & 0 & 1 & 0 & 1 & 1 & 0 \\
3 & 1 & 0 & 1 & 1 & 1 & 0 \\
4 & 0 & 0 & 1 & 1 & 0 & 1 \\
5 & 0 & 0 & 1 & 0 & 0 & 1 \\
6 & 0 & 0 & 1 & 1 & 1 & 1 \\
\hline
\end{tabular}

Table 14

Matrix $\left(S^{2}\right)$ at slicing parameter $\theta^{2}=0.20$ for example 3

\begin{tabular}{ccccccc}
\hline Sl. No. & DS & VR & DF & DC & TE & RC \\
\hline 1 & 4 & 2 & 2 & 2 & 1 & 3 \\
2 & 2 & 2 & 1 & 0 & -1 & 1 \\
3 & 2 & 1 & 3 & 1 & 0 & 2 \\
4 & 2 & 0 & 1 & 2 & 1 & 2 \\
5 & 1 & -1 & 0 & 1 & 1 & 1 \\
6 & 3 & 1 & 2 & 2 & 1 & 3 \\
\hline
\end{tabular}


Table 15

Material rating indices for example 3

\begin{tabular}{cccccc}
\hline Sl. No. & PSI & PSIN & PCI & PCIN & MRI \\
\hline 1 & 3.3174 & 1 & 8.2 & 1 & 0 \\
2 & 2.1512 & 0.6485 & 0 & 0 & 1.3515 \\
3 & 1.5459 & 0.4660 & 5.8 & 0.7073 & 0.8267 \\
4 & 1.1657 & 0.3514 & 0 & 0 & 1.6486 \\
5 & 0.4406 & 0.1328 & 0 & 0 & 1.8672 \\
6 & 2.0346 & 0.6133 & 0 & 0 & 1.3867 \\
\hline
\end{tabular}

\subsection{Example 4}

Çalışkan et al. (2013) considered a problem of appropriate tool holder material selection operating under hard milling conditions and solved it using three different MCDM techniques, i.e. extended PROMETHEE II (EXPROM2), TOPSIS and VIKOR methods. In order to satisfy the requirements of the milling conditions, six important criteria, like Young's modulus (YM) (in GPa), compressive strength (CS) (in MPa), fracture toughness (FT) (in (MPa m) $)^{1 / 2}$, material's mechanical loss coefficient (MLC), hardness (H) (in HV) and cost (C) (in $\$ / \mathrm{kg}$ ) were taken into account along with nine candidate tool holder materials. Among those criteria, cost is a non-beneficial attribute. The quantitative information for this tool holder material selection problem is given in Table 16. Applying analytic hierarchy process (AHP) technique, Çalışkan et al. (2013) determined the criteria weights as $w_{\mathrm{YM}}=0.222, w_{\mathrm{CS}}=0.175, w_{\mathrm{FT}}=0.216, w_{\mathrm{MLC}}=0.216, w_{\mathrm{H}}=0.110$ and $w_{\mathrm{C}}=0.060$, which are also used in the subsequent MCQA-based analysis. Table 17 shows the normalized decision matrix for this problem. The corresponding incidence matrix $\left(B^{3}\right)$ and $S^{3}$ matrix at a slicing parameter of 0.30 are respectively shown in Tables 18 and 19. Subsequently, the material rating indices for all the tool holder material alternatives are calculated, as shown in Table 20. Using MCQA approach, the candidate materials are ranked as 4-6-7-9-3-5-8-1-2, suggesting the superiority of tungsten carbidecobalt as the best suited material for tool holder design, followed by $\mathrm{Fe}-5 \mathrm{Cr}-\mathrm{Mo}-\mathrm{V}$. AISI 6150 obtains the last position in the ranking list. Applying EXPROM2 method, Çalışkan et al. (2013) derived a rank ordering of 7-5-6-8-3-4-9-1-2 which when compared with that obtained by MCQA approach gives an acceptable value of Spearman's rank correlation coefficient of 0.8830. A graphical representation of those two rank orderings is displayed in Fig. 2.

\section{Table 16}

Decision matrix for tool holder material selection problem (Çalıșkan et al., 2013)

\begin{tabular}{ccccccccc}
\hline S1. No. & Material & YM & CS & FT & MLC & H & C \\
\hline 1 & AISI 1020 & 210 & 330 & 54.5 & 0.00111 & 150 & 0.673 \\
2 & AISI 1040 & 212 & 632.5 & 46 & 0.00117 & 355 & 0.7045 \\
3 & AISI 4140 & 212 & 655 & 87.5 & 0.000515 & 305 & 0.864 \\
4 & AISI 6150 & 206.5 & 1575 & 38 & 0.00026 & 483 & 1.175 \\
5 & AISI 8620 & 206.5 & 360 & 111.5 & 0.00089 & 190 & 0.8665 \\
6 & Maraging steel & 187.5 & 1825 & 80 & 0.00071 & 532.5 & 6.97 \\
7 & AISI S5 & 210 & 1930 & 21 & 0.00002055 & 771 & 7.99 \\
8 & Tungsten carbide-cobalt & 593 & 4405 & 14.05 & 0.00135 & 1250 & 79.6 \\
9 & Fe-5Cr-Mo-V & 212.5 & 1655 & 120 & 0.00113 & 448.5 & 1.73 \\
\hline
\end{tabular}

\section{Table 17}

Normalized decision matrix for example 4

\begin{tabular}{cccccccc}
\hline Sl. No. & YM & CS & FT & MLC & H & C \\
\hline 1 & 0.0555 & 0 & 0.3818 & 0.8195 & 0 & 0.1864 & 0.9996 \\
2 & 0.0604 & 0.0742 & 0.3016 & 0.8646 & 0.3719 & 0.1409 & 0.9976 \\
3 & 0.0604 & 0.0798 & 0.6933 & 0.1801 & 0.3027 & 0.9936 \\
4 & 0.0469 & 0.3055 & 0.2261 & 0.654 & 0.0364 & 0.9975 \\
5 & 0.0469 & 0.0074 & 0.9198 & 0.5186 & 0.3477 & 0.9202 \\
6 & 0 & 0.3669 & 0.6225 & 0 & 0.5645 & 0.9073 \\
7 & 0.0555 & 0.3926 & 0.0656 & 1 & 0 & 0 \\
8 & 1 & 1 & 0 & 0.8345 & 0.2714 & 0.9866 \\
\hline & 0.0617 & 0.3252 & 1 & & & \\
\hline
\end{tabular}


Table 18

Incidence matrix $\left(B^{3}\right)$ at slicing parameter $\theta^{3}=0.30$ for example 4

\begin{tabular}{ccccccc}
\hline S1. No. & YM & CS & FT & MLC & H & C \\
\hline 1 & 0 & 0 & 1 & 1 & 0 & 1 \\
2 & 0 & 0 & 1 & 1 & 0 & 1 \\
3 & 0 & 0 & 1 & 1 & 0 & 1 \\
4 & 0 & 1 & 0 & 0 & 1 & 1 \\
5 & 0 & 0 & 1 & 1 & 0 & 1 \\
6 & 0 & 1 & 1 & 1 & 1 & 1 \\
7 & 0 & 1 & 0 & 0 & 1 & 1 \\
8 & 1 & 1 & 0 & 1 & 1 & 0 \\
9 & 0 & 1 & 1 & 1 & 0 & 1 \\
\hline
\end{tabular}

\section{Table 19}

Matrix $\left(S^{3}\right)$ at slicing parameter $\theta^{3}=0.30$ for example 4

\begin{tabular}{cccccccccc}
\hline Material & 1 & 2 & 3 & 4 & 5 & 6 & 7 & 8 & 9 \\
\hline 1 & 2 & 2 & 2 & 0 & 2 & 2 & 0 & 0 & 2 \\
2 & 2 & 2 & 2 & 0 & 2 & 2 & 0 & 0 & 2 \\
3 & 2 & 2 & 2 & 0 & 2 & 2 & 0 & 0 & 2 \\
4 & 0 & 0 & 0 & 2 & 0 & 2 & 2 & 1 & 1 \\
5 & 2 & 2 & 2 & 0 & 2 & 2 & 0 & 0 & 2 \\
6 & 2 & 2 & 2 & 2 & 2 & 4 & 2 & 2 & 3 \\
7 & 0 & 0 & 0 & 2 & 0 & 2 & 2 & 1 & 1 \\
8 & 0 & 0 & 0 & 1 & 0 & 2 & 1 & 3 & 1 \\
9 & 2 & 2 & 2 & 1 & 2 & 3 & 1 & 1 & 3 \\
\hline
\end{tabular}

Table 20

Material rating indices for example 4

\begin{tabular}{cccccc}
\hline Sl. No. & PSI & PSIN & PCI & PCIN & MRI \\
\hline 1 & 1 & 0.0847 & 1.2372 & 0.3111 & 1.6042 \\
2 & 0 & 0 & 1.1882 & 0.2988 & 1.7012 \\
3 & 0 & 0 & 0.8642 & 0.2173 & 1.7827 \\
4 & 0 & 0 & 0.5274 & 0.1326 & 1.8674 \\
5 & 0 & 0 & 1.6956 & 0.4264 & 1.5736 \\
6 & 0.3 & 0.0254 & 1.2186 & 0.3064 & 1.6682 \\
7 & 0.5 & 0.0424 & 0.5400 & 0.1358 & 1.8218 \\
8 & 11.8 & 1 & 3.9765 & 1 & 0 \\
9 & 1.7 & 0.1441 & 2.3736 & 0.5969 & 1.2590 \\
\hline
\end{tabular}

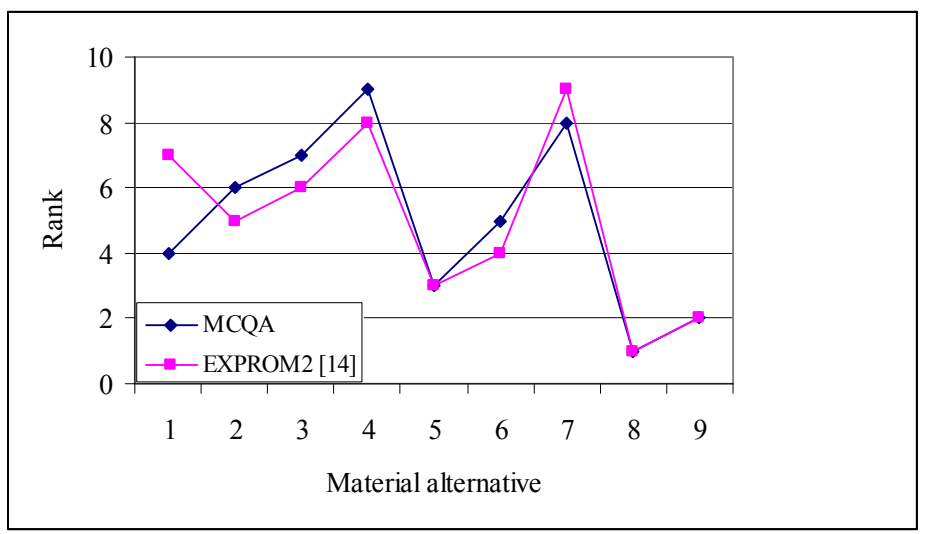

Fig. 2. Comparison of material rankings for example 4

\section{Conclusions}

In this paper, the feasibility of $Q$-analysis is explored to be an efficient MCDM tool for solving material selection problems. High Spearman's rank correlation coefficient values suggest that the rank orderings of the candidate materials derived using $Q$-analysis technique are quite accurate and 
acceptable when compared with those obtained by the past researchers. $Q$-analysis involves relatively simple calculations, just requiring 'book-keeping' type of calculations for arriving at the best course of action. It is also flexible in the sense that changing the slicing levels or criteria definitions has no effect on the final results. As this method provides both the score and rank of each material, it helps the designers to have a better insight to the material selection problems, taking into account both differences and similarities of the alternative materials. Thus, it can be applied to any complex decision-making problem having any number of alternatives and quantitative criteria.

\section{References}

Athanasopoulos, G., Riba, C.R. \& Athanasopoulou, C. (2009). A decision support system for coating selection based on fuzzy logic and multi-criteria decision making. Expert Systems with Applications, 36(8), 10848-10853.

Athawale, V.M., Kumar, R. \& Chakraborty, S. (2011). Decision making for material selection using the UTA method. International Journal of Advanced Manufacturing Technology, 57(1-4), 11-22.

Atkin, R.H. (1978). $Q$-analysis: A hard language for the soft sciences. Futures, 10(6), 492-499.

Bahraminasab, M. \& Jahan, A. (2011). Material selection for femoral component of total knee replacement using comprehensive VIKOR. Materials \& Design, 32(8-9), 4471-4477.

Çalışkan, H., Kurşuncu, B., Kurbanoğlu, C. \& Güven, Ş.Y. (2013). Material selection for the tool holder working under hard milling conditions using different multi criteria decision making methods. Materials \& Design, 45, 473-479.

Çalışkan, H. (2013). Selection of boron based tribological hard coatings using multi-criteria decision making methods. Materials \& Design, 50, 742-749.

Cavallini, C., Giorgetti, A., Citti, P. \& Nicolaie, F. (2013). Integral aided method for material selection based on quality function deployment and comprehensive VIKOR algorithm. Materials \& Design, 47, 27-34.

Chatterjee, P., Athawale, V.M. \& Chakraborty, S. (2009). Selection of materials using compromise ranking and outranking methods. Materials \& Design, 30(10), 4043-4053.

Chatterjee, P., Athawale, V.M. \& Chakraborty, S. (2011). Materials selection using complex proportional assessment and evaluation of mixed data methods. Materials \& Design, 32(2), 851860.

Chatterjee, P. \& Chakraborty, S. (2012). Material selection using preferential ranking methods, Materials \& Design, 35, 384-393.

Chauhan, A. \& Vaish, R. (2012). Magnetic material selection using multiple attribute decision making approach. Materials \& Design, 36, 1-5.

Chauhan, A. \& Vaish, R. (2013). Hard coating material selection using multi-criteria decision making. Materials \& Design, 44, 240-245.

Chin, C., Duckstein, L. \& Wymore, M.L. (1991). Factory automation project selection using multicriterion $Q$-analysis. Applied Mathematics and Computation, 46(2), 107-126.

Cicek, K. \& Celik, M. (2010). Multiple attribute decision-making solution to material selection problem based on modified fuzzy axiomatic design-model selection interface algorithm. Materials \& Design, 31(4), 2129-2133.

Dehghan-Manshadi, B., Mahmudi, H., Abedian, A. \& Mahmudi, R. (2007). A novel method for materials selection in mechanical design: Combination of non-linear normalization and a modified digital logic method. Materials \& Design, 28(1), 8-15.

Duckstein, L. (1983). Evaluation of the performance of a distribution system by $Q$-analysis. Applied Mathematics and Computation, 13(1-2), 173-185.

Duckstein, L., Bartels, P.H. \& Weber, J.E. (1988). Organization of a knowledge base by $Q$-analysis. Applied Mathematics and Computation, 26(4), 289-301.

Duckstein, L. \& Nobe, S.A. (1997). $Q$-analysis for modeling and decision making. European Journal of Operational Research, 103(3), 411-425. 
Eder, G., Duckstein, L. \& Nachtnebel, H.P. (1997). Ranking water resource projects and evaluating criteria by multicriterion $Q$-analysis: an Austrian case study. Journal of Multi-criteria Decision Analysis, 6(5), 259-271.

Edwards, K.L. (2005). Selecting materials for optimum use in engineering components. Materials \& Design, 26(5), 469-473.

Hiessl, H., Duckstein, L. \& Plate, E.J. (1985). Multiobjective $Q$-analysis with concordance and discordance concepts. Applied Mathematics and Computation, 17(2), 107-122.

Jahan, A., Mustapha, F., Ismail, M.Y., Sapuan, S.M. \& Bahraminasab, M. (2011). A comprehensive VIKOR method for material selection. Materials \& Design, 32(3), 1215-1221.

Jahan, A., Bahraminasab, M. \& Edwards, K.L. (2012). A target-based normalization technique for materials selection. Materials \& Design, 35, 647-654.

Karande, P. \& Chakraborty, S. (2012). Application of multi-objective optimization on the basis of ratio analysis (MOORA) method for materials selection. Materials \& Design, 37, 317-324.

Karande, P., Gauri, S.K. \& Chakraborty S. (2013). Applications of utility concept and desirability function for materials selection. Materials \& Design, 45, 349-358.

Maity, S.R., Chatterjee, P. \& Chakraborty, S. (2012). Cutting tool material selection using grey complex proportional assessment method. Materials \& Design, 36, 372-378.

Maniya, K. \& Bhatt, M.G. (2010). A selection of material using a novel type decision-making method: Preference selection index method. Materials \& Design, 31(4), 1785-1789.

Milani, A.S., Shanian, A., Madoliat, R. \& Nemes, J.A. (2005). The effect of normalization norms in multiple attribute decision making methods: a case study in gear material selection. Structural and Multidisciplinary Optimization, 29(4), 312-318.

Milani, A.S., Shanian, A., Lynam, C. \& Scarinci, T. (2013). An application of the analytic network process in multiple criteria material selection. Materials \& Design, 44, 622-632.

Özelkan, E.C. \& Duckstein, L. (1996). Analysing water resources alternatives and handling criteria by multi criterion decision techniques. Journal of Environmental Management, 48(1), 69-96.

Pillai, C.R.S. \& Srinivasa Raju, K. (1996). Ranking irrigation management alternatives by multicriterion analysis. International Journal of Water Resources Development, 12(3), 329-345.

Prasad, K. \& Chakraborty, S. (2013). A quality function deployment-based model for materials selection. Materials \& Design, 49, 525-535.

Rao, R.V. (2006). A material selection model using graph theory and matrix approach. Materials Science and Engineering: A, 431(1-2), 248-255.

Rao, R.V. (2008). A decision making methodology for material selection using an improved compromise ranking method. Materials \& Design, 29(10), 1949-1954.

Shanian, A. \& Savadogo, O. (2006). TOPSIS multiple-criteria decision support analysis for material selection of metallic bipolar plates for polymer electrolyte fuel cell. Journal of Power Sources, 159(2), 1095-1104.

Srinivasa Raju, K. \& Nagesh Kumar, D. (2001). Multicriterion $Q$-analysis and compromise programming for irrigation planning. Journal of Institution of Engineers (India): Civil Engineering Division, 82(1), 57-62.

Teng, J-Y., Lee, K-L. \& Huang, W-C. (2007). A fuzzy multicriterion $Q$-analysis model for international logistic-park location selection. Journal of Marine Science and Technology, 15(2), 89-103.

Thakker, A., Jarvis, J., Buggy, M. \& Sahed, A. (2008). A novel approach to materials selection strategy case study: Wave energy extraction impulse turbine blade. Materials \& Design, 29(10), 1973-1980.

Yousefpour, M. \& Rahimi, A. (2014). Characterization and selection of optimal parameters to achieve the best tribological performance of the electrodeposited $\mathrm{Cr}$ nanocomposite coating. Materials \& Design, 54, 382-389. 